\title{
Qualnet performances of grid-based clustering for WSN's routing protocols
}

\author{
Nahidah Hussein Ismail AL-Rekabi ${ }^{1}$, Basheer Yousif Mohsin AL-Sultani ${ }^{2}$ \\ ${ }^{1}$ Middle Technical University, Technical Instructors Training Institute, Iraq \\ ${ }^{2}$ Middle Technical University / Engineering Technical College-Baghdad, Mechatronics Technique Department, Iraq
}

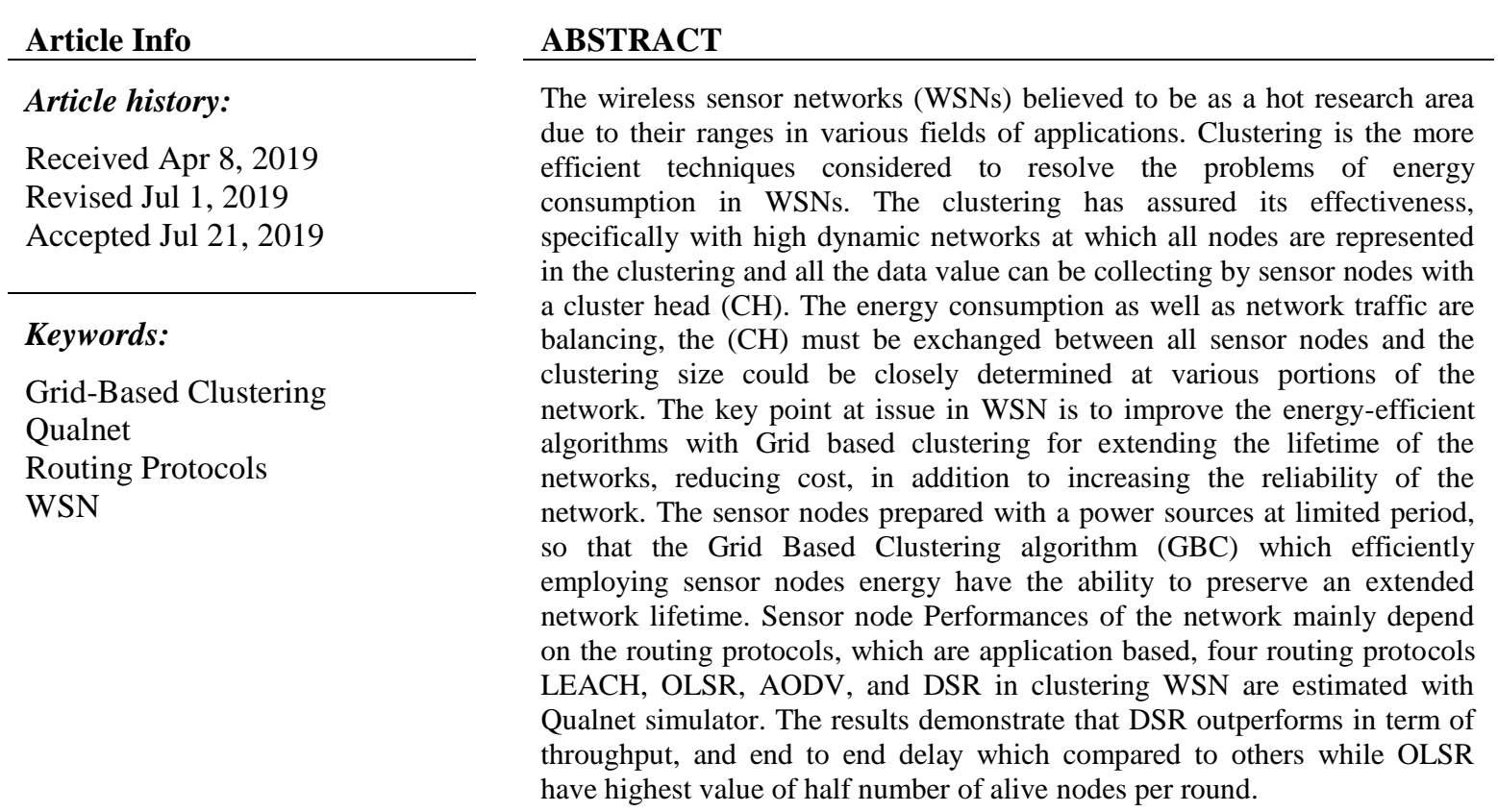

Copyright $\odot 2020$ Institute of Advanced Engineering and Science. All rights reserved.

\section{Corresponding Author:}

Basheer Yousif Mohsin AL-Sultani,

Technical Instructors Training Institute,

Middle Technical University, Baghdad, Iraq.

Email:dradnanmtu@gmail.com

\section{INTRODUCTION}

A Wireless Sensor Networks (WSN) are one of the most essential technologies for the twenty-first century. At present, an increasing number of applications with demand driven, various service sorts are accessible to fulfill the prospect of users. A large number of sensor devices are detained. Each are suitable to sense, transmit in addition to process the surrounding information. The restriction of the sensor nodes is concerned with a computational energy and communication capabilities which presents. When these sensors make precisely a network and automated, the tasks all signal processing are obligingly satisfied for the collected information from remote area in addition to dangerous areas dynamically. A different application of WSNs like biological detection, an industrial diagnostic, an environmental observation, surveillance, battlefield, smart spaces, etc. [1]. It established in physical areas, constantly collect a huge data information from the surroundings. The transmission \& receiving data by all the sensing nodes to \& from a physical wired station called base station (BS). This BS typically works like a gateway to another network. All the WSNs possess a wide-ranging of applications as useful technology in many fields of; tracking, scientific investigations, monitoring, and home security, etc. [2, 3]. 
Meanwhile each node is aiming the processing data to the sink station, where the manipulating and the decision making happened, the WSN deployment of the base station is a great interest. So, the topics concerning, power consumption, the covering of WSN in addition to reliability are all under realization. Commonly supposed that a base station will be static in nature, but they were moveable at other scenarios for collecting the sensor nodes data [4]. For achieving results with higher energy saving, base station mobility to increase the WSN lifetime is monopolized [5]. WSNs confront several designing challenges, starting with its rigid toward rules and policy modifications like operator access and commercial operation. The business requirements changes will be solid to dominate with algorithms so that it needs reprogramming or may be manual reconfirmation which is difficult for management. Other challenges come from the purpose of cost effective further the size of sensor nodes, which must be compact to be suitable to the purpose. The compacting results in the restricted memory storage, limitation at computation strength in addition to limitation of power sources [6]. The data amount in WSN to be constantly stored in a data warehouse must decrease with a certain summarized algorithm to provide accommodations to the limited memory storage. Additionally, because the node size is small, the node power is very necessary. Although it is more useful to store the energy and increase the network lifetime by utilizing more efficient routing algorithm [7].

In a wireless network, the routing protocols consider an important function in dealing with formation, arrangement, and maintenance of the network topology. The grid topology has many proceed advantaged regarding scalability and an availability to any node to send its data without central controlling [8]. These features make the routing mechanism critical. So, the demand of estimate the performance of routing protocols under different scenario is essential.

A concentration on clustering-based routing Wireless Sensor Networks in a precise area divided into a number of zones in this paper. These networks consist of a large number of locations sensors nodes within a certain field. It's a mobile node management and efficiency_enhancement of the network resources in a network zone. The nodes communication of network must complete in well-organized way. So, grid-based clustering routing technique is utilized where the grouping of nodes into a few groups considered as grids, the communication of the sensing nodes is only completed with the clustering head nodes, then_cluster heads will connect to the center processing.

In this paper, gird strategy is established on based network. A network area may be divided into grids, after that grids are grouped to form clusters. The rest of the research is organized as: Next section presents clustering with a grid-based clustering and section three describes the routing protocols in addition to the three Routing protocols mentioned. Section 4 shows the research methodology and the proposed flow chart algorithms then section five gives the evaluation and simulation result of the suggested scenario.

\section{CLUSTERING}

The distribution of WSN nodes are randomly allocated in a geographical area, some regions with such network situation get tightly occupied whereas others receiving nodes with a least number. Clustering can be considered a very suitable approach for lifetime extending of the network, energy consumption in addition to throughput of the network. Fundamentally, Clustering is the grouping process of the sensor nodes and the organization basis of applying clustering algorithms is partitioning, hierarchical, density and gridbased algorithms [9]. Cluster-based and grid-based techniques can be considered to manage with this problem. A scheme of cluster based is applied to minimize energy consumption as well as simplifying the management of the network with treating associated nodes within groups.

The scalability and robustness can be increased within a cluster-based schemes and provided a load balancing and a collected data [10]. The technique of Grid-based clustering is approved for efficient clustering that a total area can be divided within virtual grids. Grid based clustering is simpler and more feasible, and has so much advantage with respect to other clustering method [11]. The topology of grid based WSN states that cluster head represents as a base station, while the collecting of all information are within the cluster zones that is passed over the sensor nodes. Every zone is divided into own their square shape area for particular one small zone. Every zone is the combination of several sensor nodes. Every cluster head and node are doing work in each zone. A zone does not interact next to near zone. Therefore, it consumes more energy in this process. It is connected with each other. A smart grid saves the energy, reduce cost and increase reliability of the network $[12,13]$. A selection of cluster head $(\mathrm{CH})$ per grid decision is generally done by the nodes themselves, that makes it appropriate forever in a large-scale network. The techniques of Grid-based are popular owing to their simplicity, scalability, and uniformity dealing with energy consumption across the network [14]. 


\section{ROUTING PROTOCOLS}

Routing is a method to find out a path between the source node and the destination node. Routing in WSN is really challenging due to the intrinsic characteristics that differentiate these networks from the other network and also considered the act of sending the information source to destination [15]. This section describes the most four Routing protocols in WSN, these are Low Energy Adaptive Clustering Hierarchy (LEACH), AODV (Ad-hoc on-demand vector routing), OLSR (Optimized Link State Routing) and DSR (Dynamic source routing).

Reactive routing protocols called as demand routing as shown in Figure 1. In reactive routing protocols two operations are used, they are Routes discover and Route maintain. Routes discover is found all possible routes and examined Route maintains is maintained route procedure. On demand routing protocols reduced the control overhead, and increase the bandwidth of mobile station [16].

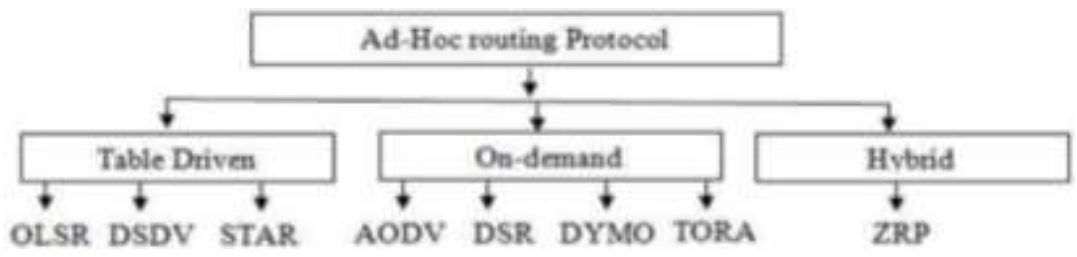

Figure 1. Routing protocols Classification

\subsection{Low Energy Adaptive Clustering Hierarchy (LEACH)}

LEACH is the first WSN clustering approach. Its functionality is categorized into rounds and probably considers the first dynamic clustering protocol that meted specifically the requirements of WSNs, and it still assists as a source for other enhanced clustering protocols for WSNs. LEACH considers hierarchical, probabilistic, distributed, and one-hop protocol [17]. It starts with a setup phase (SP) which an organization of the clusters happens, subsequently the steady-state phase (SSP) which is responsible for the information transmission to the sink happens in. A sensor in the SP determines whether have a chance to be a $\mathrm{CH}$ for the existing round. For becoming a cluster-head, each node $\mathrm{n}$ chooses a random number between 0 and 1 . When the number is less than the threshold $T(n)$, then a node becomes the cluster-head for the current round. The threshold $\mathrm{T}(\mathrm{n})$ is given in Equation (1):

$$
T(n)=\left\{\begin{array}{c}
\frac{p}{1-p\left(r \bmod \frac{1}{p}\right.}, \text { if } n \in G \\
0, \text { otherwise }
\end{array}\right.
$$

where $P$ denotes to the required percentage of CHs. Alternatively, $\mathrm{r}$ characterizes the current round. While a group of sensors is $G$, which is never considered as $\mathrm{CHs}$ in the final $1 / p$ rounds, when $\mathrm{T}(n)=1$, then for all nodes which have not been a cluster-head.

LEACH shapes clusters with a distributed algorithm, here the nodes make self-determining decisions without any localized controlling. All nodes have the same priority to become $\mathrm{CHs}$ so that for balancing the energy spent per round at any sensor node.

\subsection{Dynamic source routing (DSR)}

Dynamic Source Routing (DSR) is a type of the route on-demand in routing protocol which is largely similar to AODV. But, DSR does not rely on routing table dissimilar to AODV, nevertheless instead utilizes as a source routing at each intermediate device. DSR is mainly designed for limiting the procedure of bandwidth that is consumed by controlling packets which present in Ad hoc networks. The DSR significance mainly in reactive approach which means it eliminates the need of the network periodical broadcasting, and predominant in table driven approach $[18,19]$.

In dynamic source routing, source nodes are forwarding route request towards all nodes which are under wireless transmission range as seen in Figure 2. The source nodes generate unique request identification numbers for route request packet. When source node is not able to utilize current route for destination because of the change network topology, then it uses the route maintenance Mechanism. The target node before sending the route reply request close to the source it scans own route for the route request [20]. 


\subsection{Ad-hoc on-Demand Distance Vector Routing (AODV)}

The AODV protocol accomplishes a route discovery task with the help of control message that collect information about route request and route reply from the sender to receive the packet as shown in Figure 3. However, if a source node finds any route error message then it has the ability to restart the route process. It's working like a flat routing protocol therefore it does not need any central administrative infrastructure for handling routing system. If some nodes who want to wish communicate with the nearest nodes before they have to be start route discovery process. However, if they do not avail in route to the destination then it is called route request packet [21].

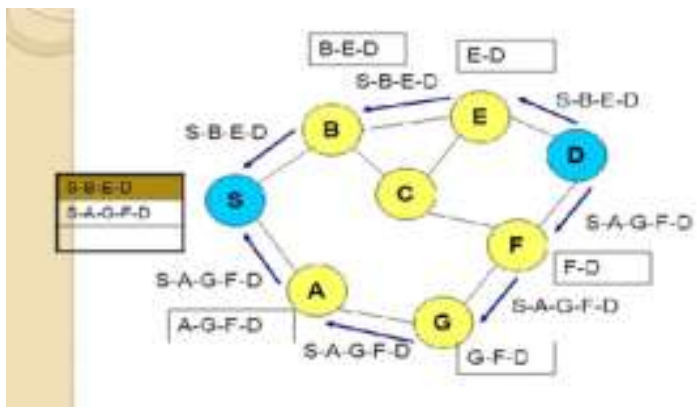

Figure 2. Route path of DSR

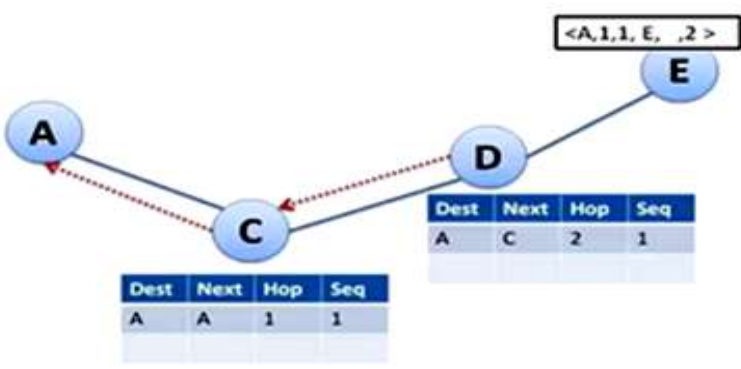

Figure 3. AODV route discovery

\subsection{Optimized Link State Routing Protocol (OLSR)}

Protocol OLSR is a proactive routing protocol enhanced for mobile ad hoc networks that can be utilized for WSN [22]. OLSR protocol enables efficient abundance of control messages through the network via chosen nodes named Multipoint Relays (MRPs). A network problem of flooding with control messages can be overcome with MRP nodes. These relays are chosen by each node in addition to the forwarding of control messages which result in a distribution process of the protocol. Along with this, the continuous nodes preserve routes to all network destinations, hence make the protocol appropriate for traffic pattern which is sporadic and random. OLSR is a promising protocol for traffic patterns where many nodes subset can be communicated with other large nodes subset, also where the pairs of source and destination will be changed over time. It is principally suited to a large and dense network. Because of this protocol is proactive nature, an advantage of available routes immediately if needed [23]. With such protocol at pure link state, all the connections with neighboring nodes are acknowledged and are abundance in the entire network.

\section{METHODOLOGY}

The concept of the grid-based cluster network can be described in Figure 4. Grid based cluster WSN main aim has reduced the power consumption at any sensor nodes for reduced traffic load [24]. In network model grid has squared shaped, each squared shaped made by zone. The setting of $n \times n$ grid can be obtained from each node. The $n \times n$ is the number Row and column. The Grid characterises the left to right and top to bottom. Left to right present the rows (n) and top to bottom present the columns (n). A $2 \times 2$ grid based network model in Figure 4 with row is shown $\mathrm{R}$ and columns shown $\mathrm{C}$ [25].

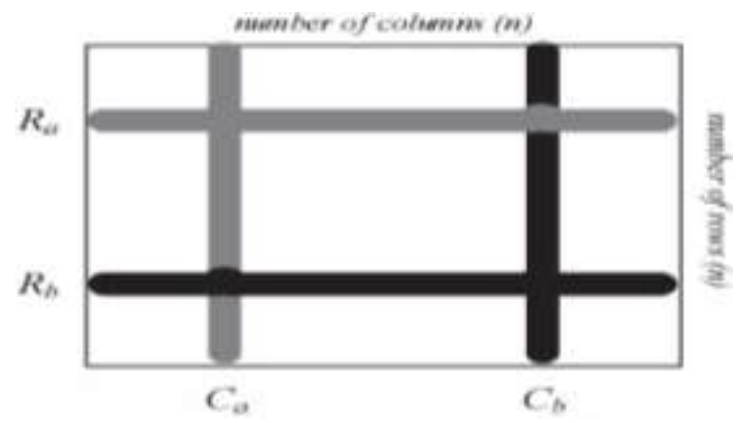

Figure 4. Grid topology 


\subsection{Flow Chart description}

In grid based cluster wireless sensor network, cluster head works like a base station in single grid based cluster and all sensor nodes transmitted and received the information from the cluster head nodes, thus the power consumption will be distributed among the nodes as shown in Figure 5 and this will provide a smart grid that save energy, reduce cost and increase reliability of the network.

The main objectives of this paper are to explore the advantages of grid topology and the classification of routing protocols as well as their features and then simulate wireless sensor routing protocols in term of network performance using Qualnet simulator.

\section{SIMULATION SETUP\& SCENARIO}

The simulation is performed using the Qualnet simulator. The Grid scenario is established as a first step by deploying a number of nodes in $1500 * 1500$ network area, then defined the simulation parameters.

\subsection{Building the Scenario}

In this scenario shown in Figure 6, after grid-based clusters will be formed, the sensing nodes can be communicated only with cluster heads, after that a communication of a cluster heads with the processing center (base Station) is done. This results in energy saving node with a distributed energy consumption as well as energy saving network.

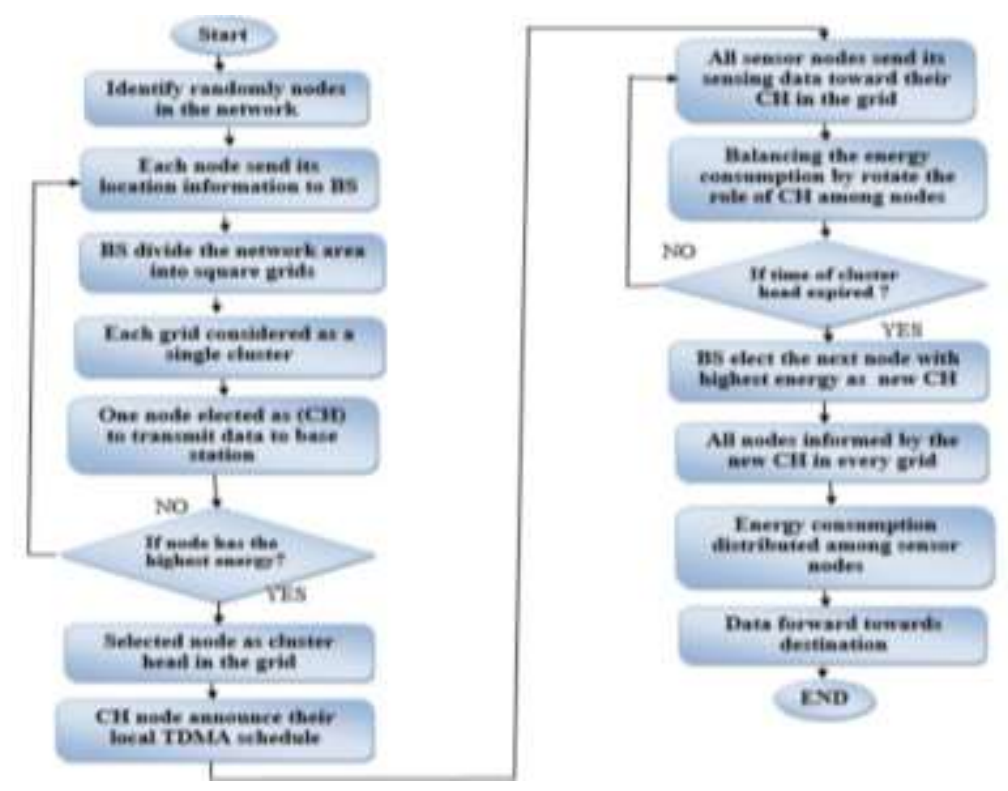

Figure 5. Grid based cluster flowchart

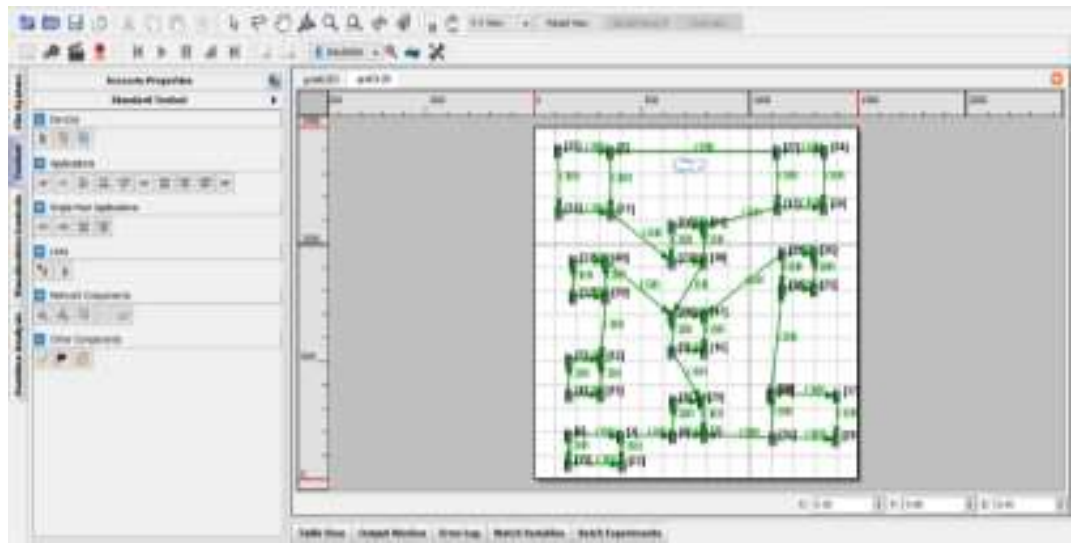

Figure 6. Building the scenario 
And then identify number of nodes (36 node) and the location of each node by choosing the grid model. Then, set the simulation values as seen in Table 1 .

Table 1. Simulation parameters

\begin{tabular}{llll}
\hline \multicolumn{1}{c}{ PARAMETER } & \multicolumn{1}{c}{ VALUE } & \multicolumn{1}{c}{ PARAMETER } & \multicolumn{1}{c}{ VALUE } \\
\hline Network type: & WSN & Network Protocol: & IPv4 \\
Number of nodes & 36 & MAC Protocol: & IEEE 802.11 \\
Terrain: & $1600-1600$ & Pause time: & $30 \mathrm{sec}$ \\
Simulation time: & $30 \mathrm{sec}$ & Physical Layer model & PHY 802.11b \\
Traffic application: & CBR & Data Rate: & $11 \mathrm{Mbps}$ \\
Number of CBR: & 10 & Transmission Power: & $25 \mathrm{dBm}$ \\
Item to send: & 4 & Noise Factor: & 10.0 \\
Packet size: & $512 \mathrm{~B}$ & Receive Sensitivity: & 83.0 \\
Interval: & $100 \mathrm{msec}$ & Number of channels: & 1 \\
CBR start-end: & $10 \mathrm{sec}$ & Wireless channel freq & $2.4 \mathrm{GHz}$ \\
Routing Protocols: & LEACH, AODV, DSR, OLSR & & \\
\hline
\end{tabular}

\subsection{Simulation Run}

To evaluate the performance of these protocols (LEACH, AODV, DSR, and OLSR) and running the scenario many times that can be seen in Figure 8, each time for one protocol and get the result of (Throughput, End-End Delay, and Packet Delivery Ratio). The Analyser result is shown in Figure 9, we observed several metric values depending on the number of nodes.

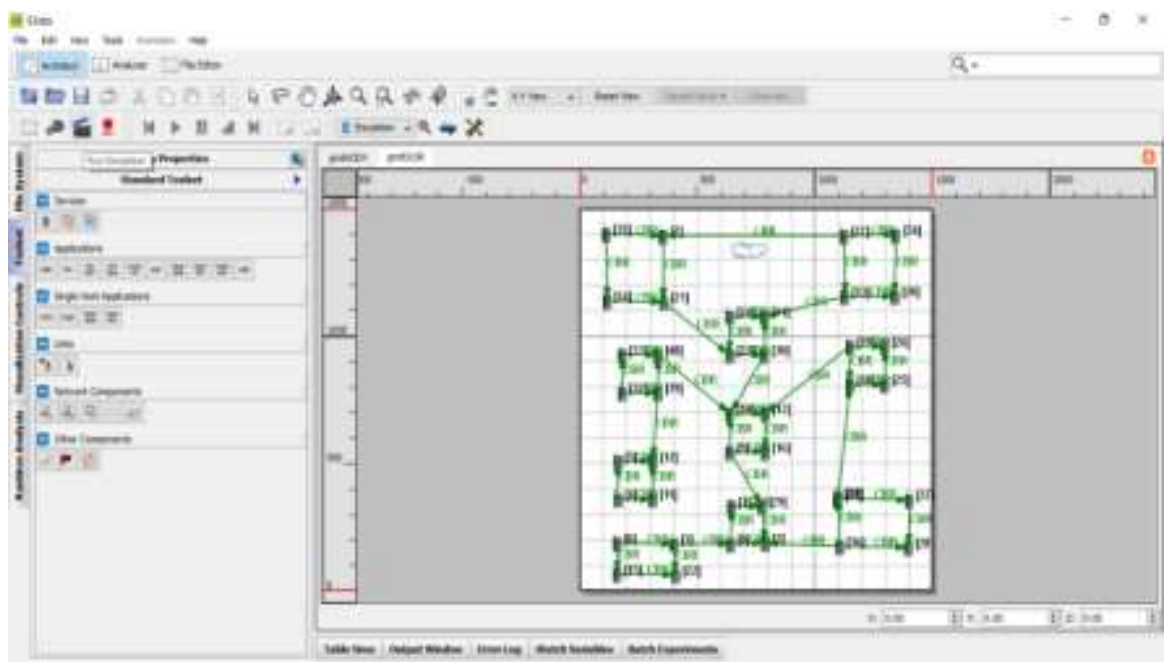

Figure 8. Run the simulation

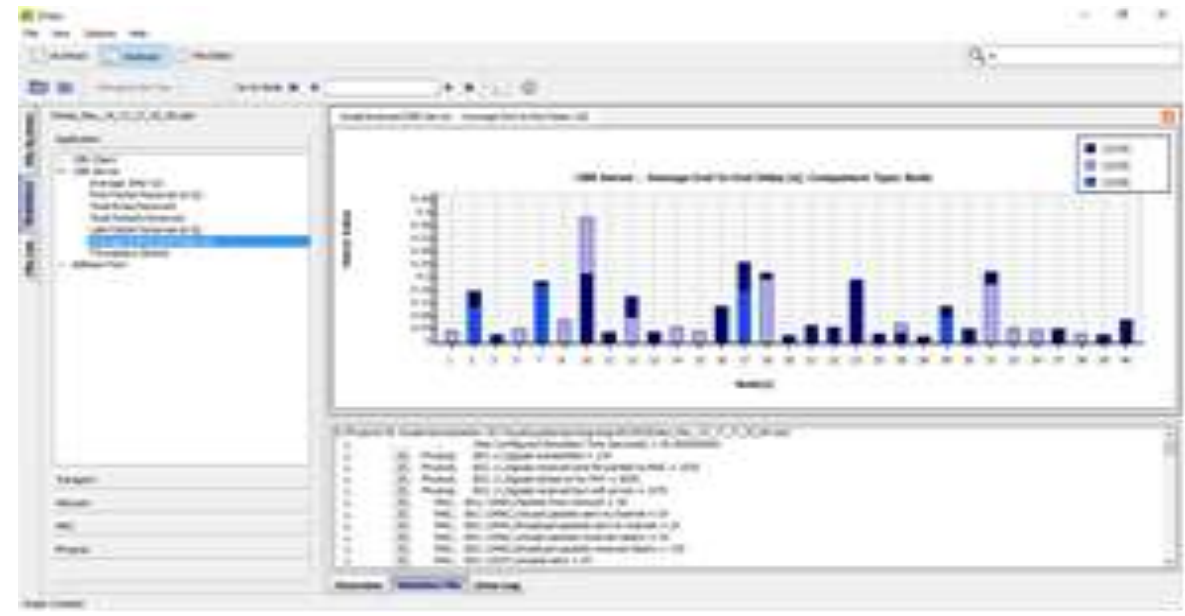

Figure 9. Results obtained from simulation 


\section{SIMULATION RESULTS}

\subsection{Average Throughput}

Throughput can be considered as the value of the network performance in certain time. From the Figure 10, it's clear the DSR outperform both the AODV and OLSR. The reason behind that is the DSR is not forwarding route request towards all nodes when it can't find the suitable route. It maintains its optimum route form other nodes under its wireless transmission range. AODV has slightly difference compare to DSR. OLSR has the worst.

\subsection{End-End Delay}

The time consume from propagation, queuing, processing, and sending is called End-End delay. It's clear, OLSR has the highest delay comparing to LEACH, AODV and DSR. DSR has the lowest delay.

\subsection{Packet Delivery Ratio}

The packet delivery ratio (PLR) is defined as how much of packet are delivered during the transmission, and it the complement of the packet dropped ratio (PLR). The PDR is calculated as as:

$$
P D R=\frac{\text { Packets delivered during transmission }}{\text { Packets sent out by sender }}
$$

From Figure $11 \& 12$, it's clear that AODV has the best packet delivery ratio comparing to others. The worst case is involved in OLSR routing protocol, but DSR perform slightly close to it.

\subsection{Half Number of Alive Nodes}

The half number of alive nodes per round can be shown in Figure 13. The result displays that the greatest performance for OLSR protocol when the mobility of the BS is considered in reducing the energy consumption, while the distance between cluster-head and BS decreases, energy dissipation also decreases.

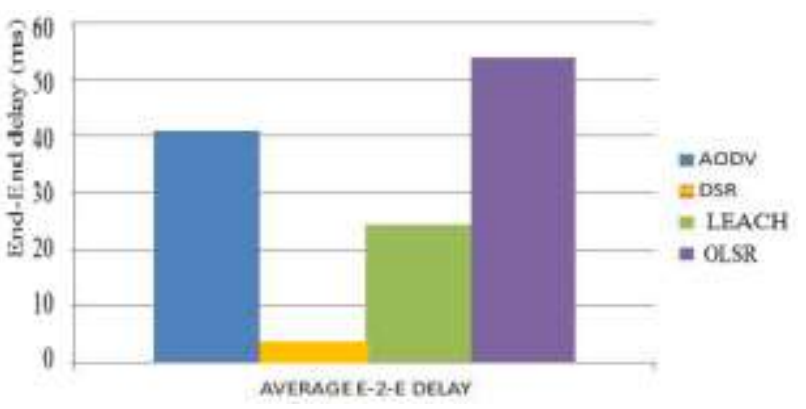

Figure 10. End-End delay for routing protocols

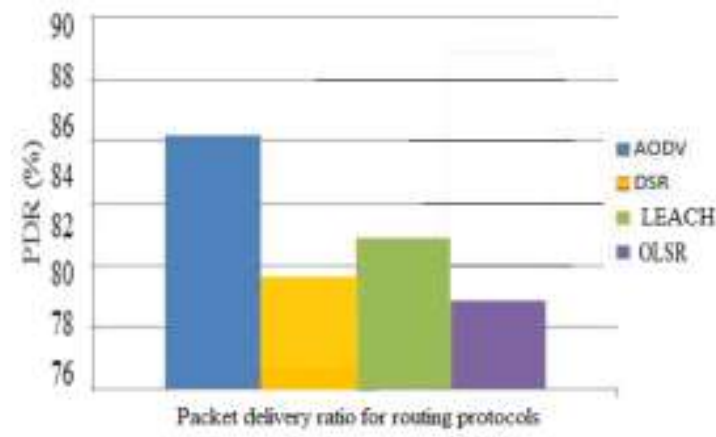

Figure 12. Packet delivery ratio for routing protocols

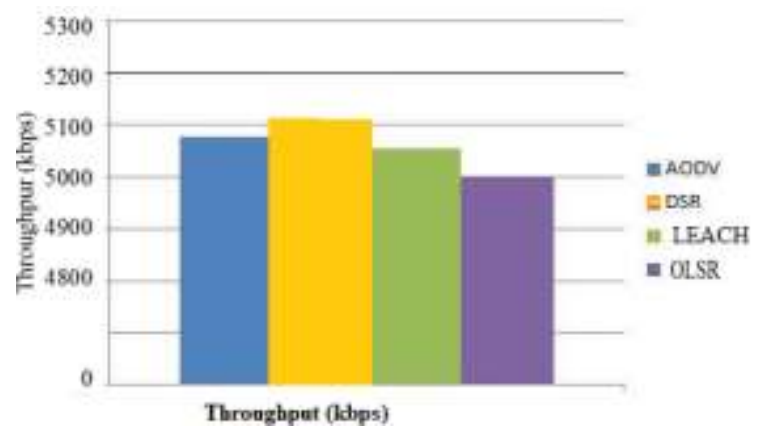

Figure 11. Average throughput for RP

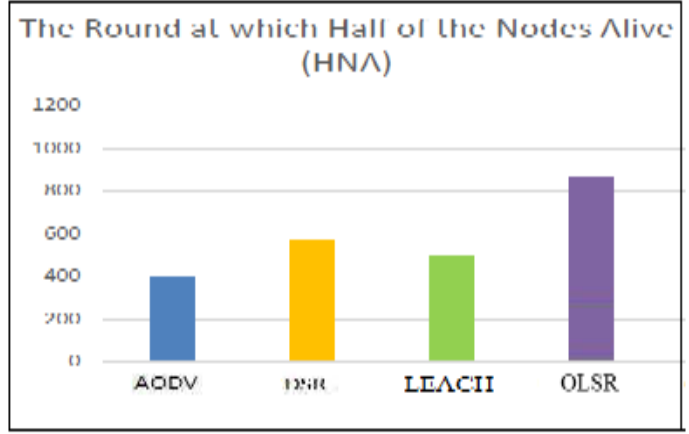

Figure 13. Half of Alive Nodes per Round for each Clustering protocols 


\section{CONCLUSION}

Grid based clustering is one of the significant topologies in the 21 st century in wireless sensor network, since its communication plays an important role in data exchange for any objects. Grid based clustering is large scale coverage area network which improve the efficiency of the network and reduce cost. From concerned paper, the techniques of up-to-date energy efficient grid-based clustering in WSN have been definitively evaluated considering different parameters such as metrics for cluster formation, energy consumption, and extending lifetime of the network. With respect to the metrics evaluated, a comparative analysis is accessible that gives a selection of suitable routing protocols for exact requirements. The indication of LEACH, OLSR, AODV, and DSR routing protocols have been acknowledged providing the concept about the applicability of a particular scheme in a certain operating environment. The results show DSR in grid-based clustering gives better throughput, packet delivery fraction, and delay performance with stabilizing and reducing energy consumption once it compared with other routing protocols.

\section{REFERENCES}

[1] X. Liu, "A survey on clustering routing protocols in wireless sensor networks," Sensors (Switzerland), vol. 12, no. 8, pp. 11113-11153, 2012.

[2] H. Farman, H. Javed, J. Ahmad, B. Jan, and M. Zeeshan, "Grid based hybrid network deployment approach for energy efficient wireless sensor networks,” Journal of Sensors, vol. 2016, Article ID 2326917, 14 pages, 2016.

[3] M. M. Kareem, M. Ismail, M. A. Altahrawi, N. Arsad, M. F. Mansor, and A. H. Ali, "Grid Based Clustering Technique in Wireless Sensor Network using Hierarchical Routing Protocol”, in 2018 IEEE 4th International Symposium on Telecommunication Technologies (ISTT), 2018, pp. 1-5.

[4] S. Jannu and P. K. Jana, "Energy efficient grid-based clustering and routing algorithms for wireless sensor networks," in Proceedings of the 4th International Conference (CSNT '14), pp. 63-68, IEEE, Bhopal, India, April 2014.

[5] R. N. Enam, R. Qureshi, and S. Misbahuddin, "A uniform clustering mechanism for wireless sensor networks," International Journal of Distributed Sensor Networks, vol. 10, no. 3, ID 924012, 2014.

[6] H.-Y. Kim, "An energy-efficient load balancing scheme to extend lifetime in wireless sensor networks," Cluster Computing, vol. 19, no. 1, pp. 279-283, 2016.

[7] Amit Kr. Kaushik "A Hybrid Approach of Fuzzy C-Means Clustering and Neural Network to Make Energy Efficient Heterogéneos Wireless Sensor Network”, International Journal of Electrical and Competer Engineering (IJECE), Vol. 6, No. 2, April 2016, pp. 674 681.

[8] Bilal Jan, H. Farman, H. Javed, B. Montrucchio, M. Khan, and Sh. Ali, "Energy Efficient Hierarchical Clustering Approaches in Wireless Sensor Networks: A Survey," Wireless Communications and Mobile Computing, Volume 2017, Article ID 6457942, 2017.

[9] Ali A. Abdulrazzaq, Adnan H. Ali, "Performance Investigation of Grid Connected Photovoltaic System Modelling Based on MATLAB Simulation", International Journal of Electrical and Computer Engineering (IJECE)8 (6), 2018.

[10] W. Wang, B. Wang, Z. Liu, L. Guo, and W. Xiong, "A cluster based and tree-based power efficient data collection and aggregation protocol for wireless sensor networks," Information Technology Journal, vol. 10, no. 3, pp. 557$564,2011$.

[11] Ismat, N., Qureshi, R., and Imam, M., "Efficient Clustering for Mobile Wireless Sensor Networks", IEEE 17th Inter. Multi Topic Conference, pp. 110-114, December, 2014.

[12] A.Thonklin and W. Suntiamorntut, "Load balanced and energy efficient cluster head election in wireless sensor networks," in Proceedings of the 8th Electrical Engineering, Electronics, Computer, Telecommunications and Information Technology (ECTI '11), pp. 421-424, Thailand, May 2011.

[13] Sharma, C. \& Kaur, J., "Literature Survey of AODV and DSR Reactive Routing Protocols". ICAET, IJCA 14-17, 2015.

[14] Hussein A. Mohammed, Adnan H. Ali," Effect of some Security Mechanisms on the Qos VoIP Application using OPNET", International Journal of Current Engineering and Technology, Vol.3, No.5, December 2013.

[15] K. Panimozhi, G. Mahadevan, "QoS Framework for a Multi-stack based Heterogeneous Wireless Sensor Network", International Journal of Electrical and Computer Engineering (IJECE), Vol. 7, No. 5, October 2017, pp. 2713 2720

[16] Kevre, P. \& Shrivastava, L. "Compare Three Reactive Routing Protocols in Grid Based Cluster Wireless Sensor Network Using Qualnet Simulator", International Journal of Applied Science and Engineering Research 3 (2): 532-539. 2014.

[17] Adnan H. Ali, Ali N. Abbas, M. H. Hassan," Performance Evaluation of IEEE802.11g WLANs Using OPNET Modeler", (AJER) Volume-02, Issue-12, pp-09-15.

[18] Adnan H. Ali, Farhood, A.D. "Design and Performance Analysis of the WDM Schemes for Radio over Fiber System with Different Fiber Propagation Losses”. Fibers. 2019, 7, 19.

[19] Ali A. Abdulrazzaq, Adnan H. Ali, "Efficiency Performances of Two MPPT Algorithms for PV System with Different Solar Panels Irradiances", International Journal of Power Electronics and Drive System (IJPEDS), Vol. 9, No. 4, December 2018, pp. 1755 1764. 
[20] A.H. Farhood, A.D., Naji, M.K., Rhaif, S.H., Ali, "Design and analysis of dual band integrated hexagonal shaped microstrip UWB antenna", Indonesian Journal of Electrical Engineering and Computer Science IJEECS, 2019, Volume 15, Issue 1, Pages 294-299.

[21] Begared Salih Hassen, Samir Abdul-Sattar Lafta, Haeeder M. Noman, Adnan Hussein Ali, "Analyzing the Performances of WSNs Routing Protocols in Grid- Based Clustering", International Journal on Advanced Science, Engineering and Information Technology IJASEIT, 2019, Volume 9, Issue 04, Pages 1211-1216

[22] Ali, A.H., Abdul-Wahid, S.N.: Analysis of self-homodyne and delayed self-heterodyne detections for tunable laser source linewidth measurements. IOSR J. Eng. 2(10), 1-6 (2012).

[23] Adnan H. Ali, "Simultaneous measurements for tunable laser source linewidth with homodyne detection", Computer and Information Science, Vol. 4, No. 4; July 2011.

[24] Jijesh J. J and Shivashankar, "Energy Efficient Routing Protocol Based on DSR", International Journal of Ad hoc, Sensor \& Ubiquitous Computing (IJASUC) Vol.7, No.5, October 2016.

[25] Adnan H A, Performance Evaluation of Wi-Fi Physical Layer Based QoS Systems on Fiber Using OPNET Modeler International Journal of Soft Computing and Engineering (IJSCE 2015) 5 Issue-3. 